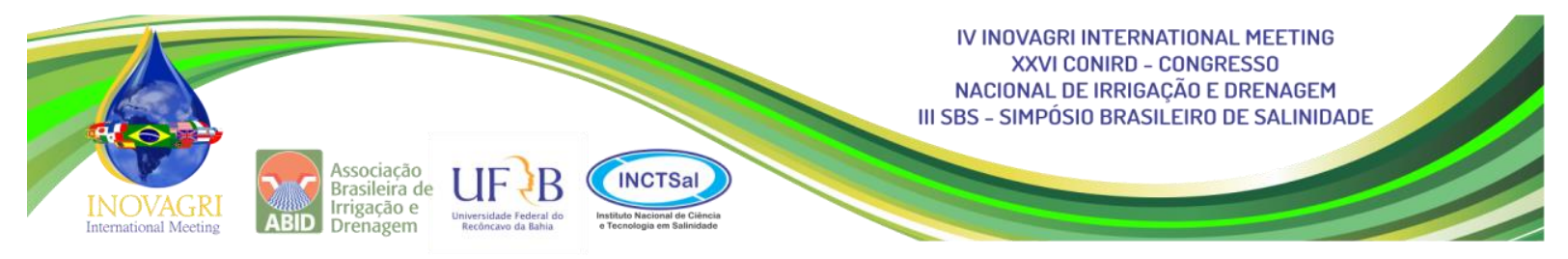

\title{
PRODUTIVIDADE DE LINHAGENS DE FEIJÃO TIPO MULATINHO NO SUBMÉDIO DO VALE SÃO FRANCISCO
}

\author{
M. Calgaro ${ }^{1}$, L. C. de Faria ${ }^{2}$, L. C. Mello ${ }^{3}$, J. M Pinto ${ }^{4}$, W. L. Simões ${ }^{5}$, M. Alves ${ }^{6}$,
}

RESUMO: O objetivo do presente trabalho foi avaliar a produtividade de diferentes linhagens de feijoeiro-comum, do tipo mulatinho no submédio do Vale São Francisco. O estudo foi implantado utilizando o delineamento experimental de blocos casualizados, sendo que cada unidade experimental foi constituída por parcelas de quatro linhas, espaçadas entre elas em 0,3 m, com quatro metros de comprimento e três repetições. $\mathrm{O}$ experimento recebeu irrigação durante todo o período de condução, sendo que a lâmina aplicada foi determinada com base na $\mathrm{ET}_{0}$ obtida por meio de uma estação agrometeorológica instalada próxima a área experimental. O sistema de irrigação utilizado foi o gotejamento superficial, com uma linha de gotejadores para cada duas linhas de plantio e emissores espaçados $0,5 \mathrm{~m}$ entre si. As produtividades das linhagens CNFM 16230 e CNFM 16220 em valores absolutos foram de 2.628,93 kg.ha-1 e 2.563,46 kg.ha-1 ${ }^{-1}$ respectivamente, não havendo diferença estatística da cultivar BRS AGRESTE, demonstrando o potencial produtivo para o Semiárido brasileiro.

PALAVRAS-CHAVE: Phaseolus vulgaris, melhoramento genético, feijão-comum.

\section{PRODUCTIVITY OF MULATTO BEAN TYPES LINEAGES IN THE BRAZILIAN NORTHEAST}

SUMMARY: The objective of the present work was to evaluate the productivity of different common bean lines, of the mulatto type in the sub midle of the São Francisco Valley. The study was implemented using a randomized complete block design, each experimental unit consisting of plots of four rows spaced $0.3 \mathrm{~m}$ apart, four meters in length and three replicates. The experiment was irrigated during the entire period of conduction, and the applied blade was determined based on $\mathrm{ET}_{0}$ obtained by means of an agrometeorological station installed near the experimental area. The irrigation system used was the surface drip, with a line of

\footnotetext{
${ }^{1}$ Doutor, Pesquisador da Embrapa Semiárido, Petrolina - Pernambuco. Email: marcelo.calgaro@embrapa.br

${ }^{2}$ Doutor, Pesquisador da Embrapa Arroz e Feijão, Santo Antônio de Jesus - Goias. Email: luis.faria@embrapa.br

${ }^{3}$ Doutor, Pesquisador da Embrapa Arroz e Feijão, Santo Antônio de Jesus - Goias. Email: leonardo.mello@embrapa.br

${ }^{4}$ Doutor, Pesquisador da Embrapa Semiárido, Petrolina - Pernambuco. Email: jose-maria.pinto@embrapa.br

${ }^{5}$ Doutor, Pesquisador da Embrapa Semiárido, Petrolina - Pernambuco. Email: welson.simoes@embrapa.br

${ }^{6}$ Bolsista, Acadêmico de Ciências Biológicas da UPE, Petrolina - Pernambuco. Email: manoelalves2013@hotmail.com
} 
drippers for every two planting lines and emitters spaced $0.5 \mathrm{~m}$ apart. The yields of the CNFM 16230 and CNFM 16220 strains in absolute values were 2,628.93 kg.ha-1 and 2,563.46 kg.ha- ${ }^{-1}$, respectively, and there was no statistical difference of the cultivar BRS AGRESTE, demonstrating the productive potential for the semi-arid Brazilian.

KEYWORDS: Phaseolus vulgaris, genetical enhancement, common bean.

\section{INTRODUÇÃO}

O feijão-comum (Phaseolus vulgaris L.) está presente na alimentação diária de grande parte da população brasileira e constitui-se em uma das importantes fontes nutricionais para milhões de brasileiros.

O cultivo de feijão tem uma participação significativa na dieta da população de diversas regiões do país, entre elas a região Nordeste. No submédio do Vale do São Francisco a cultura é uma das opções para os produtores logo após a colheita da cebola no segundo semestre do ano. Porém, as condições de insuficiência e de irregularidade nas precipitações no Semiárido brasileiro limitam a produção do feijão na região.

A produtividade no estado de Pernambuco oscila em função da qualidade da semente utilizada, do sistema de cultivo, do espaçamento empregado, da irregularidade das chuvas, entre outros fatores. Em razão disso, tem-se verificado produtividades de até $1.200 \mathrm{~kg} / \mathrm{ha}$ no Agreste Meridional e de 1.500 a 2.000 kg/ha no Vale do São Francisco (Costa \& Lopes, 1999).

Sendo assim, uma pesquisa liderada pela Embrapa Arroz e Feijão, em parceria com diversas outras unidades da Embrapa, incluindo a Embrapa Semiárido, teve início em 2008, com estudos de identificação de genitores que associem características para compor os blocos de cruzamentos com cultivares adaptadas as condições do nordeste brasileiro, visando formação de populações segregantes para seleção de genótipos de feijão-comum melhorados e com características agronômicas desejáveis (Calgaro et al., 2009).

O presente trabalho teve como objetivo avaliar a produtividade de 17 linhagens de feijão-comum, do tipo mulatinho no submédio do Vale do São Francisco.

\section{MATERIAL E MÉTODOS}

O estudo foi realizado na estação experimental da Embrapa Semiárido, localizada no Perímetro Irrigado de Bebedouro, Município de Petrolina, PE, (latitude: 9º9’ S, longitude: 
$40^{\circ} 22^{\prime}$ W, altitude: 365,5 m). A classificação climática, segundo Köppen, (1918) é do tipo BSWh, ou seja, tropical semiárido (Reddy \& Amorim Neto, 1983). A temperatura média anual é de $28,3^{\circ} \mathrm{C}$, variando entre 21 e $32^{\circ} \mathrm{C}$, com uma evaporação média anual em torno de $2000 \mathrm{~mm}$ e umidade relativa do ar média anual de 68,5. A velocidade média do vento é de 2,3 $\mathrm{m} . \mathrm{s}^{-1}$ e o brilho solar é de 3000 horas anuais.

O solo do local é classificado como Latossolo vermelho amarelo distrófico (EMBRAPA, 2006). As precipitações ocorrem entre novembro e abril, tendo como principal característica a irregularidade de distribuição, com um volume médio anual em torno de 426 mm (EMBRAPA, 2016).

Para a condução do experimento foram semeadas 17 linhagens, sendo elas CNFM 16230, CNFM 16220, CNFM 16218, CNFM 16028, CNFM 16016, CNFM 16213, CNFM 16228, CNFM 16229, CNFM 16225, CNFM 16226, CNFM 16027, CNFM 16231, CNFM 16026, CNFM 16050, CNFM 16012, CNFM 16219 e CNFM 16029 e 1 testemunha (BRS AGRESTE) de feijão-comum do tipo mulatinho, organizados em blocos inteiramente casualizados, com três repetições. Cada parcela foi constituída de 4 linhas de plantas com 4 metros de comprimento, espaçadas $0,3 \mathrm{~m}$ entre as linhas. Os tratos culturais realizados foram os recomendados por Araújo et al., 1996, para a cultura do feijoeiro. A adubação seguiu a recomendação técnica para o cultivo do feijão-comum para a região, tendo sido aplicados 20 kg.ha- ${ }^{-1}$ de N, 20 kg.ha- ${ }^{-1}$ de $\mathrm{P}_{2} \mathrm{O}_{5}$ e $20 \mathrm{~kg} \cdot \mathrm{ha}^{-1}$ de $\mathrm{K}_{2} \mathrm{O}$ na adubação de fundação e na adubação de cobertura, $40 \mathrm{~kg} \cdot \mathrm{ha}^{-1}$ de $\mathrm{N}$, aos 20 dias após a emergência.

O experimento foi semeado no dia 22 de junho de 2016, e para proporcionar pleno desenvolvimento a cultura foi instalado um sistema de irrigação por gotejamento, com gotejadores superficiais espaçados $0,3 \mathrm{~m}$ entre si e vazão média nominal de 2,0 L.h ${ }^{-1}$. A irrigação foi manejada com base na evapotranspiração de referência (Allen et al., 1998), e do coeficiente de cultivo (kc), sugeridos por Silveira \& Stone, (2016), conforme apresentados no Quadro 1. Para isso a umidade do solo foi elevada a capacidade de campo logo após o termino da semeadura e posteriormente seguiu-se a reposição da água evapotranspirada conforme a $\mathrm{ET}_{0}$, com intervalos de rega de 2 dias.

A produção dos genótipos foi obtida colhendo-se no momento da maturação completa, as duas fileiras centrais de 4 metros de comprimento de cada parcela, equivalente a $2,4 \mathrm{~m}^{2}$, sendo determinadas as produtividades médias por hectare de cada genótipo. Para a comparação das médias foi utilizado o teste de Scott-Knott a 5\% de probabilidade. 


\section{RESULTADOS E DISCUSSÃO}

Observou-se na Tabela 1, que as produtividades médias dos materiais estudados variaram de 2.748,42 kg.ha-1 com a testemunha BRS AGRESTE até 1.846,78 kg.ha-1 alcançado pela linhagem CNFM 16029. Essa diferença em termos percentuais representa apenas 4,35\% de redução de produtividade quando comparado a testemunha, sendo que, os genótipos não apresentaram diferença estatística significativa entre si.

O Nordeste é a região com uma das menores produtividades do Brasil, ficando atrás somente da região norte. A produtividade média para o estado de Pernambuco segundo a CONAB (2016) é de $1.484 \mathrm{~kg} \cdot \mathrm{ha}^{-1}$.

A produtividade da linhagem CNFM 16230 foi de 2.628,93 kg.ha ${ }^{-1}$, sendo este valor muito acima da produtividade média do Estado de Pernambuco demonstrando a viabilidade de produção dos materiais estudados para as condições de cultivo do vale do Submédio São Francisco. Assim, pode-se afirmar que as linhagens estudadas têm grande potencial para o cultivo nas condições em que o estudo foi desenvolvido.

O ciclo de médio dos genótipos neste ensaio foi de 80 a 85 dias considerado normal para as condições em que o ensaio foi realizado segundo CATALOGO (2017). Durante o ciclo foi fornecida durante uma lâmina de água de 440,95 mm via irrigação, sendo esse volume de água considerado adequado ao pleno desenvolvimento da cultura.

\section{CONCLUSÕES}

As linhagens avaliadas apresentam potencial para produção no submédio do Vale do São Francisco, com produtividade média superior a média do Estado de Pernambuco para a safra 2016.

\section{AGRADECIMENTOS}

Aos estagiários e bolsistas que trabalharam na pesquisa e aos funcionários do Campo Experimental de Bebedouro que tornaram possível a realização desse trabalho. 


\section{REFERÊNCIAS BIBLIOGRÁFICAS}

ALLEN, R. G.; PEREIRA, L. S.; RAES, D.; SMITH, M. Crop evapotranspiration: Guidelines for computing crop water requirements. Rome: FAO, 1998. 300 p. (FAO - Irrigation and Drainage Paper, 56).

ARAÚJO, RICARDO S.; RAVA, Carlos A.; STONE, Luis F.; ZIMMERMANN, Maria J. O. Cultura do Feijoeiro Comum no Brasil. Piracicaba: Associação Brasileira para Pesquisa da Potassa e do Fosfato, 1996.

CALGARO, M.; MENEZES, E. A.; PELOSO, M. J. D.; GUIMARÃES, C. M. Adaptação de genótipos de feijoeiro comum promissores para pesquisa em biofortificação e tolerância a seca no semiárido brasileiro. In: REUNIÃO ANUAL DE BIOFORTIFICAÇÃO NO BRASIL, 3, 2009, Aracaju. Anais... Aracaju: Embrapa Tabuleiros Costeiros, 2009. 1 CDROM

CATÁlogO de cultivares de feijão comum. 2. ed. Santo Antonio de Goiás: Embrapa Arroz e Feijão, 2017. 27 p.

COMPANHIA NACIONAL DE ABASTECIMENTO (CONAB). $12^{\circ}$. Levantamento da safra brasileira de grãos 2015/2016. Disponível em: http://www.conab.gov.br/ OlalaCMS/uploads/arquivos/16_09_09_15_18_32_boletim_12_setembro.pdf. Acesso em: 08 set. 2016.

COSTA, A.F. da; LOPES, L. H. de O. Recursos geneticos e melhoramento do feijoeiro comum em Pernambuco. In: QUEIROZ, M. A. de; GOEDERT, C. O.; RAMOS, S. R. R. (Ed.). Recursos genéticos e melhoramento de plantas para o Nordeste brasileiro. Petrolina: Embrapa Semi-Árido; Brasília, DF: Embrapa Recursos Genéticos e Biotecnologia, 1999.

EMBRAPA. Centro Nacional de Pesquisa de Solos. Sistema Brasileiro de Classificação de Solos. 2 ed. Rio de Janeiro: Embrapa Solos, 2006.

EMBRAPA. Centro de Pesquisa Agropecuária do Tropico Semiárido. Médias anuais da estação agrometeorológica de Bebedouro. Petrolina, 2014. Disponível em: http://www.cpatsa.embrapa.br:8080/servicos/dadosmet/ceb-anual.html. Acesso em: 19 jun. 2016.

KÖPPEN, W. Klassification der klimate nach temperatur, niederschlag und jahreslauf. Petermanns Geographische Mitteilungen, Gotha, v. 64, p. 193- 203, 1918. 
PIMENTEL-GOMES, Curso de Estatística Experimental, 1985. Piracicaba-SP. ESALQ/USP

SILVA, O. F. da; WANDER, A. E. O feijão-comum no Brasil: passado, presente e futuro. Santo Antônio de Goiás: Embrapa Arroz e Feijão, 2013. 63p. (Embrapa Arroz e Feijão. Documentos, 287).

SILVEIRA, P; M da; STONE, L; F. Manejo de irrigação. IN: Agencia de Informação Embrapa Feijão. Disponível em: http://www.agencia.cnptia.embrapa.br/Agencia4/AG01/arvore/AG01_86_1311200215104. html. Acesso em 13 de novembro 2016.

SCOTT, A. J.; KNOTT, M. A cluster analysis method for grouping means in the analysis of variance. Biometrics, Washington, v. 30, n.2 p.507-512, 1974.

Quadro 1. Coeficiente de cultura $(\mathrm{Kc})$ propostos por SILVEIRA E STONE (2016) para as três principais fases do ciclo da cultura do feijoeiro-comum.

\begin{tabular}{lcc}
\hline \multicolumn{1}{c}{ Fases da cultura } & Duração da fase (dias) & Kc \\
\hline Germinação - Início da floração & 35 & 0,69 \\
Floração - Início do desenvolvimento de vagens & 25 & 1,28 \\
Desenvolvimento de vagens - Maturação & 20 & 1,04 \\
\hline
\end{tabular}

Tabela 1. Médias das produtividades de feijão-comum $\left(\mathrm{kg} \cdot \mathrm{ha}^{-1}\right)$.

\begin{tabular}{|c|c|c|}
\hline Ordem & Nome & $\begin{array}{c}\text { Produtividade média } \\
\left(\text { kg.ha }^{-1}\right)\end{array}$ \\
\hline 1 & BRS AGRESTE* & $2.748,42$ a \\
\hline 2 & CNFM 16230 & $2.628,93 \mathrm{a}$ \\
\hline 3 & CNFM 16220 & $2.563,46$ a \\
\hline 4 & CNFM 16218 & $2.562,43 \quad \mathrm{a}$ \\
\hline 5 & CNFM 16028 & $2.505,46$ a \\
\hline 6 & CNFM 16016 & $2.459,90 \quad$ a \\
\hline 7 & CNFM 16213 & $2.438,69$ a \\
\hline 8 & CNFM 16228 & $2.387,01 \quad \mathrm{a}$ \\
\hline 9 & CNFM 16229 & $2.359,93$ a \\
\hline 10 & CNFM 16225 & $2.320,06 \quad \mathrm{a}$ \\
\hline 11 & CNFM 16226 & $2.280,65 \mathrm{a}$ \\
\hline 12 & CNFM 16027 & $2.280,04 \mathrm{a}$ \\
\hline 13 & CNFM 16231 & $2.244,64$ a \\
\hline 14 & CNFM 16026 & $2.235,74$ a \\
\hline 15 & CNFM 16050 & $2.230,74$ a \\
\hline 16 & CNFM 16012 & $2.164,57 \quad \mathrm{a}$ \\
\hline 17 & CNFM 16219 & $1.993,69 \mathrm{a}$ \\
\hline 18 & CNFM 16029 & $1.846,78 \quad \mathrm{a}$ \\
\hline
\end{tabular}

